\title{
On the Regress Argument for Infinitism
}

\author{
John Turri \\ john.turri@gmail.com
}

\begin{abstract}
This paper critically evaluates the regress argument for infinitism. The dialectic is essentially this. Peter Klein argues that only an infinitist can, without being dogmatic, enhance the credibility of a questioned non-evident proposition. In response, I demonstrate that a foundationalist can do this equally well. Furthermore, I explain how foundationalism can provide for infinite chains of justification. I conclude that the regress argument for infinitism should not convince us.
\end{abstract}

Infinitism offers a theory of justification as well as a solution to the epistemic regress problem. Discussion of infinitism goes back at least to Aristotle. ${ }^{1}$ However, compared to its main non-skeptical competitors, foundationalism and coherentism, its resources remain largely underdeveloped, and its potential benefits, should there be any, unappreciated. This paper critically evaluates one argument for infinitism: the regress argument. The dialectic is essentially this. It has been argued that only an infinitist can, without being dogmatic, enhance the credibility of a questioned non-evident proposition. I respond by demonstrating that a foundationalist can do this equally well. Furthermore, I explain how foundationalism can provide for infinite chains of justification.

Through a series of articles over the better part of the last decade, Peter Klein has done more than anybody to revive the fortunes of infinitism, thrusting it back onto the philosophical scene. ${ }^{2}$ According to Klein, the regress problem "concerns the ability of reasoning to increase the rational credibility of a questioned proposition."

The Regress Problem can be put as follows: Which type of series of reasons and the account of warrant associated with it, if any, can increase the credibility of a non-evident proposition? Can a series with repeating propositions do so? Can one with a last member do so? Can one that is non-

1 Posterior Analytics, $72 \mathrm{~b} 5 \mathrm{ff}$.

2 See, e.g., Klein (1998), (1999), and (2005a). See also Fantl (2003). 
repeating and has no last member do so $?^{3}$

A non-evident proposition is one about which there could be "credible disagreement." One sure sign of a non-evident proposition is that our "epistemic peers could sincerely disagree with us about [its] truth." In such a case, the proposition lacks "the desired level of credibility" for us. How might we, through reasoning, restore some of that credibility, once some measure of doubt has set in? That is the key question for Klein, and what in this paper I shall refer to as the regress problem.

Klein evaluates four main competing solutions: foundationalism, two forms of coherentism, and infinitism. The test is whether a "self-conscious practitioner" of a theory can, once questioned by an interlocutor, "employ" it to "increase the rational credibility" of a non-evident proposition. It is important to note that, according to Klein, "it is not crucial what degree of credibility is at stake." The question is whether a self-conscious practitioner can enhance credibility at all. ${ }^{4}$ If a self-conscious practitioner of a theory can do this, I shall say that the theory solves the regress problem.

Klein's thesis is that only infinitism can solve the regress problem. In order to establish his thesis, Klein argues for two further theses: (1) neither coherentism nor foundationalism can solve the regress problem, and (2) infinitism can solve the regress problem. Assuming that (3) foundationalism, coherentism, and infinitism exhaust the alternatives, Klein's thesis follows. Call the argument from 1 - 3 to Klein's thesis the regress argument for infinitism.

I will show that accepting what Klein says in defense of 2 should lead us to reject 1 ,

3 Klein (2005a, 132). Elsewhere Klein puts matters differently. "I will explain how the infinitist can provide a solution to the epistemic regress problem[,] which is, as I see it, how to avoid arbitrariness in belief without falling into dogmatism." See Klein (2005b, 154).

4 Klein $(2005 a, 132)$. 
and consequently his overall argument. The reasons that Klein offers for thinking that infinitism can solve the regress problem provide an equally adequate basis for concluding that foundationalism can solve the regress problem, too, thereby casting doubt on $1 .{ }^{5}$

Klein distinguishes two sorts of coherentism, warrant-transfer and warrantemergent. He rejects warrant-transfer coherentism because it endorses question-begging circular reasoning as a way of enhancing the credibility of a proposition, whereas surely any chain of reasoning that cites $\mathrm{P}$ as a reason for believing $\mathrm{P}$ cannot increase the credibility of $\mathrm{P}^{6}$ He rejects warrant-emergent coherentism because it is just a "one-step" version of foundationalism, and foundationalism cannot solve the regress problem. This places more weight on Klein's argument that foundationalism cannot solve the regress problem.

According to Klein, the essence of foundationalism is the claim that warrant or justification "aris[es] autonomously in so-called basic propositions and [is then] transferred to other propositions through permissible forms of inference." noted that, in the course of his discussion, Klein neither argues nor presupposes that foundationalism is incorrect in its contention that some beliefs, properly basic beliefs, are “autonomously" warranted or justified, where this positive epistemic status is achieved not

5 It is worth noting that we need not completely answer the important question "just what makes one proposition or belief a (good) reason for another?" in order to evaluate the regress argument for infinitism. The argument purports to establish a certain formal constraint on good reasons: a good reason must be supported by an infinite and non-repeating series of further reason. Settling the matter at hand thus goes some but not all the way toward a theory of good reasons. A complete theory would settle whether there are any further substantive requirements on good reasons. A complete theory far surpasses what I am capable of in the present paper, as it would require, among other things, evaluating a vast range of arguments for and against epistemological externalism, as well as addressing whether there are any higher-order requirements on epistemically appropriate belief, e.g., whether and in what sense a subject must believe that the reason for her belief is adequate in order for it to be adequate. (Thanks to an anonymous referee for alerting me that this issue might be on readers' minds.)

6 Klein $(2005 a, 134)$.

7 Klein (2005a, 132). 
by inference from further beliefs or reasons, but instead accrues to the basic belief in virtue of its being $\mathrm{F}$, where ' $\mathrm{F}$ ' denotes the favored foundationalist property that confers such status, whether it be indubitability, being caused by a reliable process, etc. ${ }^{8}$

Klein tests foundationalism by means of an imaginary dialogue between a selfconscious practicing foundationalist, Fred, and a doubting antagonist, Doris. I will now present a dialogue, which is essentially modeled on Klein's, but presented in a way most conducive to making my main critical point shortly. In my dialogue, Fran is the foundationalist and Dan the doubter.

Before proceeding, I should note that many will object to Klein's method here, on the grounds that he has confused the property of being justified, or even that of enhancing justification, with the process of showing that one is justified. Why think that explicit, reflective reasoning is the only way to enhance one's justification for a non-evident proposition, once it has been questioned? Couldn't the foundationalist reject this assumption, on the grounds that foundationalism provides other ways of regaining credibility lost in the face of an aggressive interlocutor? I am expressly setting aside all such worries here. For the sake of argument, I grant that Klein is correct about the dialectical nature of justification.

Now for the dialogue. ${ }^{9}$ Fran says that the tree just off the ninth green is an elm. Let 'P' denote the proposition that the tree just off the ninth green is an elm. Dan asks Fran

8 Klein $(2005 a, 133)$. Here we can see why Klein considers warrant-emergent coherentism to be a thinly disguised version of foundationalism: "In this case, the foundational property, $\mathrm{F}$, which all warranted propositions have, is that each is a member of a set of coherent propositions," Klein (2005a, 135).

9 Much of this is very close paraphrase of Klein's dialogue. However, some is also taken verbatim from Klein's dialogue, and, except where it seemed absolutely critical that the reader be aware that I'm using Klein's exact words, I don't use quotation marks to indicate where I have used Klein's exact words. I've changed some names and variables in the dialogue, which rendered the intermittent use of quotation marks and bracketed material both cumbersome and distracting. Let this footnote stand as official attribution, to Klein, of all intellectual credit for the structure, tone, and basic wording of the dialogue. 
something that makes her believe that she had better have reasons for believing P. Fran responds by pointing out that the tree has leaves characteristic of elms. Call this reason ' $R_{1}$ '. Dan inquires about the status of Fran's acceptance of $R_{1}$. Fran responds by citing the shape and texture of the leaves. Call this reason ' $R_{2}$ '. Dan inquires about the status of Fran's acceptance of $\mathrm{R}_{2}$. This goes on until Fran, as a self-conscious practicing foundationalist, reaches what she considers to be a properly basic belief, B. Dan presses further. Fran resists at this point, claiming that $\mathrm{B}$ has foundational property $\mathrm{F}$, and so is properly basic, and thus "doesn't need a reason." 10 Dan grants that B is F, and thus properly basic, and not in need of a reason, but asks Fran whether properly basic beliefs are at least likely to be true.

With respect to Dan's last question, Fran has three options: affirm, deny, or withhold. If she denies, then, although holding B is not arbitrary (remember, Klein is granting for the sake of argument that B is a properly basic belief), using B as a reason for $\mathrm{R}_{\mathrm{n}}$ is arbitrary. If she withholds, then, from her own point of view, she ought not to use $\mathrm{B}$ as the basis for further beliefs. If it is not good enough to affirm in and of itself, then how could it be proper to deploy it as a basis for affirming something else? Neither of those options, then, allows Fran to regain any of P's lost credibility. What if she affirms? If she affirms, then $\mathrm{B}$ non-arbitrarily can serve as a reason $\mathrm{R}_{\mathrm{n}}$, but only because the regress has continued. Fran has a very good reason for holding B, namely, B has F and F-beliefs are likely to be true. It would now be legitimate to ask Fran to offer a reason for thinking that $\mathrm{B}$ is $\mathrm{F}$, and a reason for thinking that F-beliefs are likely to be true. Therefore, "a

10 I doubt that foundationalism need be committed to the claim that properly basic beliefs don't stand in need of reasons. This is an artifact of Klein's characterization of foundationalism, and I will not stop to question its accuracy, since it is tangential to my project in this paper. Elsewhere, Klein $(2004,168)$ remarks, "I take it that foundationalists hold, at a minimum, that some propositions are prima facie justified in the absence of further reasons." 
practicing foundationalist cannot increase the rational credibility of a questioned proposition through reasoning." 11

Before proceeding further, let us pause to take stock of the progress Fran made before answering Dan's last question. Fran had articulated the following justificatory structure:

$$
\mathrm{B} \rightarrow \mathrm{R}_{\mathrm{n}} \rightarrow \ldots \rightarrow \mathrm{R}_{2} \rightarrow \mathrm{R}_{1} \rightarrow \mathrm{P}
$$

in support of the original non-evident proposition P. It is consistent with the statement of foundationalism that ' $\mathrm{n}$ ' in ' $\mathrm{R}_{\mathrm{n}}$ ' be arbitrarily finitely large. (Which is not to say that it would necessarily be inconsistent with foundationalism if ' $n$ ' were infinite; more on this below.)

We want a view that endorses neither circular reasoning nor arbitrariness. Yet, Klein maintains, there is something to the foundationalist idea that some propositions are epistemically prior to others, and something to the warrant-emergent coherentist idea that warrant emerges from a proposition's being embedded in an appropriate set of supporting propositions. Klein's version of infinitism (which he calls "warrant-emergent infinitism," but which I shall continue to call simply "infinitism") purportedly speaks to all these needs. It avoids vicious circularity because it forbids a proposition from appearing in its own evidential ancestry or series of supporting reasons; it avoids arbitrariness because it says that, for each reason $r$ in a series supporting a belief, there is a further reason, available to the subject, supporting $r$.

But can a practicing infinitist increase the credibility of a questioned non-evident proposition? Unless a practicing infinitist can do this, then, at least with respect to the regress problem, infinitism is no better off than foundationalism. This brings me to my

11 Here ends the close paraphrase of Klein's dialogue. 
main point, which takes shape in light of Klein's response to an objection against

infinitism raised by Sextus Empiricus. I will argue that Klein's response to Sextus reveals

that, by Klein's own lights, the practicing foundationalist can, and in Fran's case does,

increase the credibility of a questioned non-evident proposition.

I first quote the passage from Sextus and then Klein's response at length:

[Sextus says:] The Mode based upon regress ad infinitum is that whereby we assert that the thing adduced as proof of the matter proposed needs a further proof, and this again another, and so on ad infinitum, so that the consequence is suspension [of judgment], as we possess no starting-point for our argument. ${ }^{12}$

[Klein responds:] Now, if efficacious reasoning required that warrant originate in and be transferred from a basic proposition, this criticism would be just. But for the reasons given above, infinitism eschews such a view. The 'starting point' of reasoning is, as Peirce says: doubt. A proposition becomes questionable and, consequently, it lacks the desired rational credibility.

Reasoning scratches the itch. The infinitist holds that finding a reason for the questioned proposition, and then another for that reason, etc., places it at the beginning of a series of propositions each of which gains warrant and rational credibility by being part of the series. Warrant increases not because we are getting closer to a basic proposition but rather because we are getting further from the questioned proposition. But the Pyrrhonist is correct that the infinitist's conception of reasoning precludes assenting to a non-evident proposition. Dogmatism is incompatible with practicing infinitism. Warrant, and with it rational credibility, increases as the series lengthens; but the matter is never completely settled. ${ }^{13}$

Warrant and rational credibility increase because we get further from the questioned proposition. Rational credibility increases as the series of reasons offered in support lengthens. Recall Fran's progress. She started with $\mathrm{P}$. Then she adduced $\mathrm{R}_{1}$. Then she adduced $\mathrm{R}_{2}$. And she kept on going until she got to $\mathrm{B}$. She lengthened the series supporting $\mathrm{P}$, and thus increased the rational credibility of $\mathrm{P}$. Therefore, the self-practicing foundationalist (qua self-practicing foundationalist) can enhance the credibility of a nonevident proposition. Moreover, consistent with foundationalism, the length of the series can

12 Quoted in Klein (2005a, 137).

13 Klein (2005a, 137 - 138), emphasis added. 
increase to any arbitrarily large finite cardinality, so the prospects for increasing it to the level required for knowledge are at least hopeful. As Klein puts it, “As the series lengthens, warrant and credibility increase. Nothing prevents it increasing to the degree required for knowledge," since it is implausible "that knowledge requires the highest possible degree of warrant or absolutely credible belief," which only an infinitely long series could provide. ${ }^{14}$

Does the fact that Fran's reasoning would eventually end with B, were she to continue, wreck the supposed enhancement in justification? Nothing in Klein's response to Sextus indicates that it would. Klein does not take it as a premise of his reasoning that a chain of reasons must be infinite to do its epistemological work; rather, that is his conclusion. And clearly it would be unhelpful to assume the thesis of infinitism in order to argue for it.

Perhaps the fact that, as Klein puts it, practicing infinitism is incompatible with dogmatism is enough to set it apart from foundationalism? Grant that falling into dogmatism is an intellectual vice incompatible with enhancing the credibility of a questioned non-evident proposition. This would aid Klein's argument only if practicing foundationalism was incompatible with not falling into dogmatism. But foundationalism need not lead to dogmatism: nothing prevents Fran from practicing a version of foundationalism, according to which such matters are "never completely settled."15

I conclude that Klein's regress argument for infinitism ought not to convince us. By the standard in play, foundationalism provides just as satisfactory a solution to the regress

4 Klein (2005a, 138).

15 Some might wonder what implications this has for versions of foundationalism that allow for matters to be completely settled. Call such a view dogmatic foundationalism. (Not to be confused with James Pryor's (2000) foundationalist dogmatism.) I do not wish to rule out viable dogmatic foundationalist views, and my argument here does not require that I do so. My point is that, even granting for the sake of argument that dogmatism is a vice, non-dogmatic foundationalism remains a viable alternative. 
problem as does infinitism. Of course, some will object to Klein's standards; that is, they will deny that merely increasing the length of a series of reasons adduced to support the original belief can, all by itself, enhance the justification (or warrant, or rational credibility) with which the original belief is held. Let me be clear: I am not defending the standard in question. My point is that such a standard provides no basis for preferring infinitism to foundationalism.

At this stage it would be natural to wonder, is warrant (or justification, or credibility) a matter of having more and more reasons, as Klein insists, or a matter of basing your belief in non-evident propositions on properly basic beliefs, as the foundationalist claims? ${ }^{16}$ But the two options are not incompatible. 17 A series of reasons, supporting a belief in a questioned non-evident proposition, need not have a last member in order to have a foundational (properly basic) member, as I shall presently demonstrate.

Foundationalism is consistent with there being available to the subject an infinite, non-repeating series of reasons, of the sort the infinitist prizes. In other words, foundationalists needn't limit themselves to finite series of reasons. ${ }^{18}$ Suppose that Fran sees that it is 2:05. Suppose further that she practices a version of foundationalism according to which such external-world beliefs can be properly basic, and that in the present case her belief that it is 2:05 satisfies all the relevant criteria. Now Fran asserts that it is past 2:00. Dan asks Fran something, which makes her think that she had better have reasons for believing that it is past 2:00. She responds that she believes it is past 2:00 because it is past 2:04. Dan presses further: why think that it is past 2:04? Because it is past

16 Thanks to an anonymous referee for putting this question to me.

17 It is worth remembering that we here focus on a dialectical conception of epistemic merit. Many foundationalists concern themselves with a thoroughly non-dialectical brand of epistemic merit; see, e.g., Pryor (2004).

18 Ben Fiedor and Ernest Sosa independently suggested in conversation examples similar to the following one. 
2:04:30. Why think that? Because it is past $2: 04: 45$. Why think that? Because it is past 2:04:52.5. Why think that? Because it is past 2:04:56.25. And so on. Each time Dan makes a further request, Fran will respond by inching halfway closer to 2:05. But proceeding this way ensures that she will approach the limit of, but never arrive at, 2:05. In other words, she has available to her an infinite series of non-repeating reasons, each of which is entailed by its successor. Moreover, the foundationalist has a principled story to tell about how each member of this infinite series gets justified for her: namely, she can see that it is 2:05! ${ }^{19}$

\section{References}

Fantl, Jeremy. (2003). “Modest Infinitism.” Canadian Journal of Philosophy, 33:4.

Klein, Peter. (1998). "Foundationalism and the Infinite Regress of Reasons." Philosophy and Phenomenological Research, 58:4.

Klein, Peter. (1999). "Infinitism and the Infinite Regress of Reasons." Philosophical Perspectives, 13, 1999 (ed. James Tomberlin).

Klein, Peter. (2004). "What IS Wrong with Foundationalism is that It Cannot Solve the Epistemic Regress Problem.” Philosophy and Phenomenological Research, 68:1.

Klein, Peter. (2005a). "Infinitism Is the Solution to the Regress Problem." In Steup and Sosa (Eds.).

Klein, Peter (2005b). “Infinitism's Take on Justification, Knowledge, Certainty, and Skepticism." Veritas, 50:4.

Pryor, James. 2000. "The Skeptic and the Dogmatist.” Noûs, 34:4.

Pryor, James. 2004. "What's Wrong with Moore's Argument?" Philosophical Issue, 14, 2004, Epistemology (ed. Ernest Sosa and Enrique Villanueva).

Steup, Matthias and Ernest Sosa. (Eds.) (2005). Contemporary Debates in Epistemology. Malden, MA: Blackwell.

19 For feedback and discussion that helped improve this paper, I thank Ben Fiedor, Peter Klein, Ernest Sosa, and two anonymous referees. 